\title{
Probability Model of Corrosion-Induced Cracking Time in Chloride-Contaminated Reinforced Concrete
}

\author{
Chunhua Lu, Jinmu Yang, and Ronggui Liu \\ Faculty of Civil Engineering and Mechanics, Jiangsu University, Zhenjiang 212013, P.R.China
}

\begin{abstract}
Corrosion-induced concrete cover cracking caused by chloride ion is an important indication of durability limit state for marine reinforced concrete (RC) structures and can ultimately determine the structural service life. In this paper, considering the random nature of factors affecting the corrosion cracking process, a probabilistic model which expands on the deterministic model of cover cracking time is developed by using Monte Carlo simulation technique. The results showed that the time to corrosion cracking can be modelled by the Weibull distribution. Finally, the probabilistic analysis for the cracking time is applied to an in-site RC bridge girder with four different durability design specifications. It is found that the mean and $90 \%$ confidence interval of the cover cracking time will increase with the improvement of durability design level, which means that the difficulty in precise prediction with deterministic model will augment accordingly.
\end{abstract}

Keywords: reinforce concrete, corrosion, cover cracking, probability model, Monte Carlo simulation

\section{INTRODUCTION}

For chloride-contaminated reinforced concrete $(R C)$ structures, reinforcement corrosion has been recognized as one of the major causes of structural performance degradation (Liu \& Weyers, 1998; Oh \& Jang, 2003; Vu \& Stewart, 2000). With the progress of corrosion, the volume expansion of rust products, which is about two to six times the volume of steel consumed, produces increasing mechanical forces to the surrounding concrete, which can eventually result in the damage to the structures in the form of (longitudinal) cracking, spalling and delamination of concrete cover, and loss of bond between concrete and reinforcement (Liu \& Weyers, 1998; Steward \& Mullard, 2007; Vu \& Stewart, 2005). The cracking of concrete cover due to steel corrosion is an important criterion for analyzing and evaluating the service life of the corroded RC structures. Once these cracks in the cover concrete appear, a path for a quicker ingress of aggressive elements to the steel bars may be provided, and the corrosion-induced deterioration processes will be accelerated. Therefore, the appearance of the first corrosion crack is a key indication for the endof-service-life of structural concrete, and it is widely accepted that the state of cover cracking induced by corrosion is identified as the serviceability limit state of RC structures (Steward \& Mullard, 2007; Vu \& Stewart, 2005).

For the problem of the corrosion-induced cover cracking in concrete, lots of laboratory tests and field investigations have been conducted by many researchers (Alonso, Andrade, Rodriguez, \& Diez,
1998; Andrade, Alonso, \& Molina, 1993; Liu \& Weyers, 1998; Oh, Kim, \& Jang, 2009; Rasheeduzzafar, AlSaadoun, \& Al-Gahtani, 1992; Vu \& Stewart, 2005), and some theoretical models predicting the time of cover cracking have been proposed (Bazant, 1979; Bhargava, Ghosh, Mori, \& Ramanujam, 2005; Li, Melchers, \& Zheng, 2006; Liu \& Weyers, 1998; Lu, Jin, \& Liu, 2011; Maaddawy \& Soudki, 2007; Morinaga, 1988). Except for the above researches about analytical models, some researchers tended to model the cracking behavior using nonlinear fracture mechanics or finite-element method (Ahmed, Maalej, \& Mihashi, 2007; Chen \& Mahadevan, 2008; Hansen \& Saouma, 1999; Pantazopoulou \& Papoulia, 2001). These efforts have made great contributions in analyzing the corrosion of reinforcement and relevant cover cracking. However, there are still some differences between the observed data and predicted values made by the above-mentioned models. Some researchers (Kirkpatrick, Weyers, AndersonCooka, \& Sprinkel, 2002; Suo \& Stewart, 2009; ThoftChristensen, 2000; Val \& Trapper, 2008) have used the probabilistic method to predict the service life of corroded RC structure, which can enhance the accuracy and realism of time prediction. Therefore, it is valuable to use probability method to predict the time from corrosion initiation to cover cracking.

Based on the theoretical model of time to cover cracking proposed by Lu et al. (2011), as given in Eq. 1, this paper intends to propose a probability model for the cover cracking time by using Monte Carlo simulation technology. Then, the given probabilistic procedure is 
applied to a RC bridge girder in marine environment with four durability design levels, which can provide some reference to engineering design.

$$
\begin{aligned}
& t_{c r}=26.80 \cdot \frac{d+k c}{(n-1) \cdot i_{\text {corr }}}\left\{\left[\left(0.3+0.6 \frac{c}{d}\right) .\right.\right. \\
& \left.\left.\frac{f_{c t}}{E_{c e f}}\left[\frac{\left(r_{0}+c\right)^{2}+r_{0}^{2}}{\left(r_{0}+c\right)^{2}-r_{0}^{2}}+v_{c}\right]+1+\frac{2 \delta_{0}}{d}\right]^{2}-1\right\}
\end{aligned}
$$

where $t_{\mathrm{cr}}$ is the time from corrosion initiation to cover cracking (year); $c$ and $d$ are cover thickness $(\mathrm{mm})$ and steel diameter $(\mathrm{mm})$, respectively; $n$ is the mean ratio of volume of corrosion products to that of consumed iron, which is assumed to be 2.5-3.0 here; $i_{\text {corr }}$ is the corrosion current density $\left(\mu \mathrm{A} / \mathrm{cm}^{2}\right) ; \delta_{0}$ is the thickness of the porous zone which is typically in the range of 10-20 $\mu \mathrm{m}$ (Maaddawy \& Soudki, 2007); $v_{c}$ is Poisson's ratio of concrete with $0.18-0.2$; $r_{0}=\mathrm{d} / 2+\delta_{0}$; and $f_{\mathrm{ct}}$ and $E_{\text {cef }}$ are tensile strength and effective elastic modulus of concrete, respectively (Lu et al., 2011).

\section{PROBABILITY MODEL OF COVER CRACKING TIME}

\subsection{Probabilistic time modeling}

It is clearly known that all parameters affecting the corrosion process of reinforcement, such as cover thickness, corrosion current density, mechanical properties of concrete, composition of corrosion products, etc. possess random nature. Therefore, it may be more logical to involve those uncertainties in the service life predictions. To represent uncertainty about a variable, it is customary when using probability theory to let such variables be random variables and to associate with them a probability density function (PDF) based on data and other information. Based on the Monte Carlo simulation technique, the joint PDF of cover cracking time can be obtained. Thus, the cumulative distribution function (CDF) of the cracking time can be defined as

$$
F_{t}(\tau)=\operatorname{Pr}\{t \leq \tau\}=\int_{t \leq \tau} f(\bar{X}) d \bar{X}
$$

where $\bar{X}$ is the vector of the random variables to be taken into account and $f(\bar{X})$ is the joint PDF of vector $\bar{X}$.

\subsection{Establishment of probabilistic model}

To establish the probabilistic model of cracking time, some basic analytical parameters about $c$, $i_{\text {corr }}, f_{\text {ct }}$, and $E_{\mathrm{c}}$ are adopted from Liu and Weyers's experiment (Liu \& Weyers, 1998). Based on the statistical information given in literatures (Steward \& Mullard, 2007; Thoft-Christensen, 2000; Tikalsky, Pustka, \& Marek, 2005), the distribution relationships for these input variables are estimated, and the results are given in Table 1. Nevertheless, given the complexity of composition of corrosion products, the statistical parameters for ratio $n$ have not been well understood yet, and it is assumed to follow normal distribution with mean $=2.7$ and coefficient of variation $(\mathrm{COV})=0.2$, see Table 1 .

Table 1. Statistical parameters of random variable.

\begin{tabular}{lccll}
\hline $\begin{array}{l}\text { Random } \\
\text { variable }\end{array}$ & Mean & COV & Distribution & \multicolumn{1}{c}{ Reference } \\
\hline$c(\mathrm{~mm})$ & $27 / 48 / 70$ & 0.16 & Normal & $\begin{array}{l}\text { Tikalsky et al. } \\
(2005)\end{array}$ \\
$\delta_{0}(\mu \mathrm{m})$ & 15 & 0.20 & Lognormal & $\begin{array}{l}\text { Thoft-Christensen } \\
(2000)\end{array}$ \\
$i_{\text {corr }}(\mu \mathrm{A} /$ & $3.75 / 2.41 /$ & 0.18 & Normal & $\begin{array}{l}\text { Thoft-Christensen } \\
(2000)\end{array}$ \\
$\left.\mathrm{cm}^{2}\right)$ & 1.79 & & & $\begin{array}{l}\text { Steward and } \\
\text { ct }\end{array}$ \\
$E_{\mathrm{c}}(\mathrm{MPa})$ & 3.3 & 0.13 & Normal & $\begin{array}{l}\text { Mullard }(2007) \\
\text { Steward and } \\
\text { Mullard }(2007)\end{array}$ \\
$n$ & 27 & 0.12 & Normal & \\
\hline
\end{tabular}

By Monte Carlo simulation, the histograms of frequency density with $0.1 \mathrm{a}$ interval for specimens with $c=27,48$, and $70 \mathrm{~mm}$, respectively, are obtained and shown in Figure 1. Through the KS test with a level of significance of $5 \%$, it can be found that cover cracking time $t_{\mathrm{cr}}$ follows the Weibull distribution, which is also suggested by Thoft-Christensen (2000). The corresponding distribution functions, $W(0.68,2.9,0)$, $W(1.18,2.13,0.5)$, and $W(2.15,1.95,1.0)$ for $c=27$, 48 , and $70 \mathrm{~mm}$, respectively, are also plotted in Figure 1.

Figure 2 shows the cumulative distribution functions (CDF) of the fitted Weibull distributions for three test specimens. For 90\% confidence interval between $5 \%$ quantile and $95 \%$ quantile, the ranges of cover cracking time of $[0.29,1.03]$ years, $[0.79,2.49]$ years, and $[1.47,4.78]$ years are obtained for $c=27,48$, and $70 \mathrm{~mm}$, respectively, as shown in Figure 3 . The observed times given by Liu \& Weyers (1998) also be included in Figure 3. From Figures 2 and 3 , it can be seen that the mean and $90 \%$ confidence interval of $t_{\mathrm{cr}}$ increase with the increase in cover thickness for the same strength concrete, which was recognized and also confirmed by the data reported by Alonso, Andrade, Rodriguez, \& Diez (1998). As seen in Figure 3, the test times of $t_{\mathrm{cr}}$ observed by Liu and Weyers (1998) are in the range of $90 \%$ confidence interval and follow nearly with the mean curve, which indicates that the probabilistic model expressed by Weibull function is acceptable in predicting the cover cracking time. 


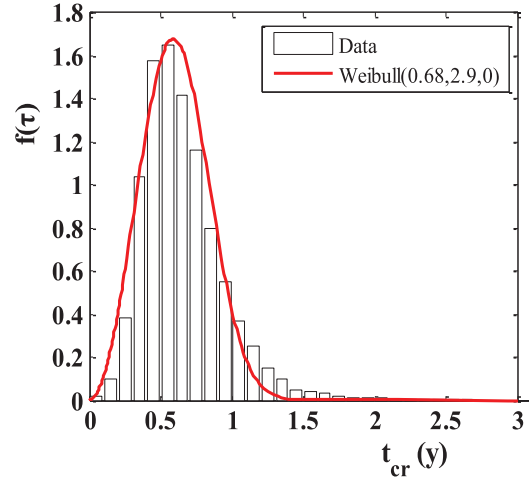

(a) $c=27 \mathrm{~mm}$

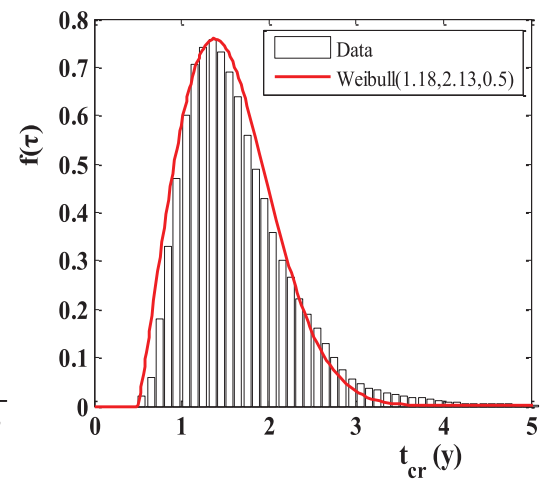

(b) $c=48 \mathrm{~mm}$

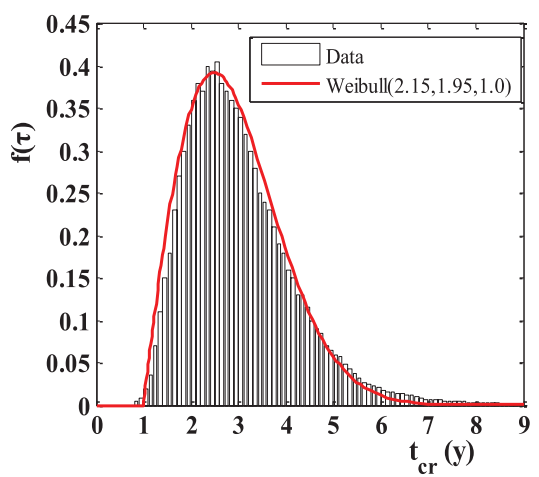

(c) $c=70 \mathrm{~mm}$

Figure 1. Frequency histogram and its fitting curves for specimens in the literature (Liu \& Weyers, 1998).

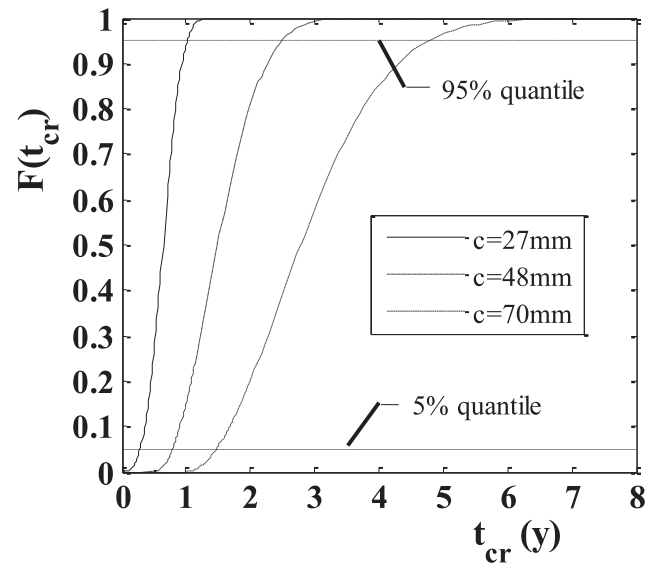

Figure 2. CDFs of $t_{\mathrm{cr}}$ for three test specimens.

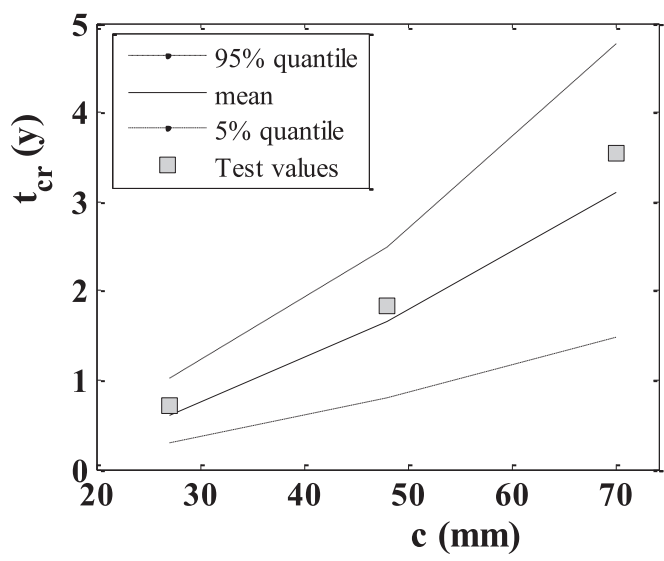

Figure 3. Mean, $90 \%$ confidence interval, and test times of $t_{\text {cr }}$

\section{MODEL'S APPLICATION TO IN-SITE RC BRIDGE GIRDER}

For natural corrosion process in RC members, the corrosion current density is usually time variant due to the formation of rust products, which reduce the diffusion of the iron ions away from the steel surface (Liu \& Weyers, 1998; Tikalsky et al., 2005). Vu and
Steward (Vu \& Stewart, 2000) suggest that corrosion current density, $i_{\text {corr }}$, may thus be expressed as a timedependent variable (see Figure 4):

$$
i_{\text {corr }}(t)=i_{\text {corr }}(1) \cdot \alpha \cdot\left(t-t_{0}\right)^{\beta} \quad\left(t-t_{0} \geq 1 \text { year }\right)
$$

where $t-t_{0}$ is the time since corrosion initiation, and $\alpha$ and $\beta$ are two constants. If the corrosion rate is time invariant, then $\alpha=1$ and $\beta=0$. If corrosion rate reduces with time, then $\alpha=0.85$ and $\beta=-0.3$ ( Vu \& Stewart, 2000). $i_{\text {corr }}(1)$ is the corrosion current density at the start of corrosion propagation $\left(\mu \mathrm{A} / \mathrm{cm}^{2}\right)$, and for relative humidity of $75 \%$ and temperature of $20^{\circ} \mathrm{C}$, it can be expressed as

$$
i_{\text {corr }}(1)=37.8(1-W / C)^{-1.64} / C
$$

where $W / C$ is the water-cement ratio of concrete.

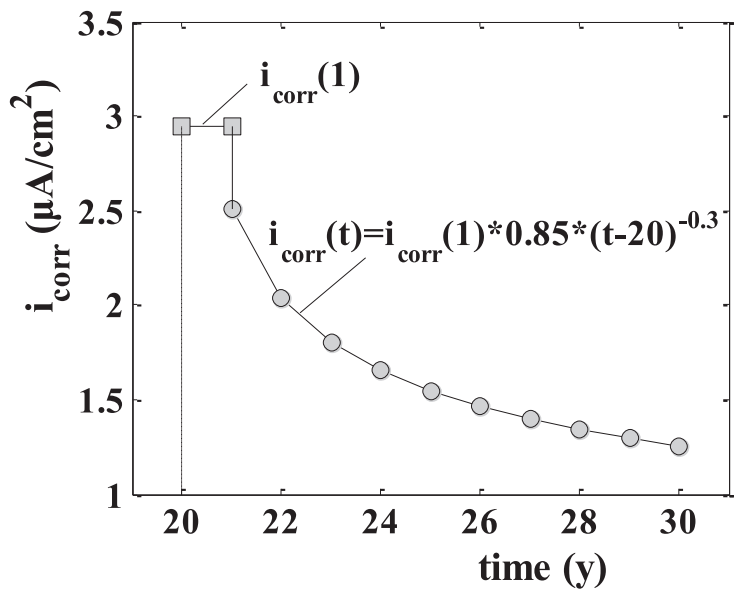

Figure 4. Time-dependent $i_{\text {corr }}$ suggested by $\mathrm{Vu}$ and Steward with $t_{0}=20$ years (Vu and Stewart, 2000).

For simplicity, it is assumed that during the period from corrosion initiation to cover cracking, the corrosion current density would be time invariant, and the value of $i_{\text {corr }}$ is supposed to be calculated by Eq. 4. Then based on Liu and Weyers's experiment, in which the WIC ratio for three 
specimens varied between 0.43 and 0.45 (Liu \& Weyers, 1998), the measured corrosion rates are compared with the calculations predicted by Eq. 4 , as shown in Figure 5. It can be concluded from Figure 5 that the corrosion current density expressed by Eq. 4 is effective in predicting the corrosion rate during the period of corrosion cracking and will be used in the following application.

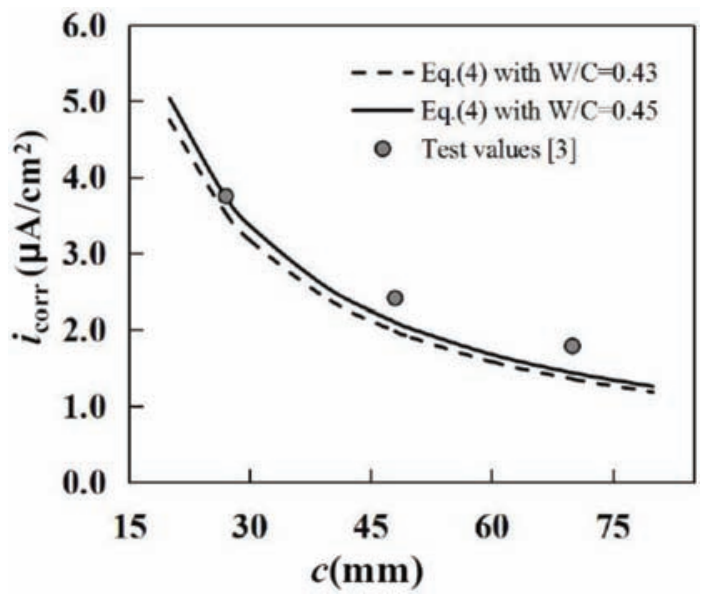

Figure 5. Comparison between test values and calculations for $i_{\text {corr }}$

To illustrate the application of probabilistic model to an in-site structural scenario, a comparative analysis considering the variability of concrete cover and concrete compressive strength is developed for a RC bridge girder. For this study, the WIC ratio, concrete tensile strength, and elastic modulus of concrete are dependent variables on the concrete compressive strength. Here, WIC ratio is estimated from Bolomey's formula (Vu \& Stewart, 2000), as expressed in Eq. 5.

$$
W / C=\frac{27}{f_{c}^{\prime}+13.5}
$$

where $f_{c}^{\prime}$ is the concrete compressive strength of a standard test cylinder in megapascal.

Four durability design specifications are considered as followings:

(1) Low durability: $c=25 \mathrm{~mm}, W / C=0.60$ $\left(f_{c}^{\prime}=31.5 \mathrm{MPa}, f_{\mathrm{ct}}=5.28 \mathrm{MPa}, E_{\mathrm{c}}=25.3 \mathrm{GPa}\right) ;$

(2) Moderate durability: $c=40 \mathrm{~mm}, W / C=0.50$ $\left(f_{\mathrm{c}}^{\prime}=40.5 \mathrm{MPa}, f_{\mathrm{ct}}=5.98 \mathrm{MPa}, E_{\mathrm{c}}=28.6 \mathrm{GPa}\right)$;

(3) High durability: $c=60 \mathrm{~mm}, W / C=0.40$ $\left(f_{\mathrm{c}}^{\prime}=54 \mathrm{MPa}, f_{\mathrm{ct}}=6.91 \mathrm{MPa}, E_{\mathrm{c}}=33.1 \mathrm{GPa}\right)$; and

(4) Extreme durability: $c=80 \mathrm{~mm}, W / C=0.35$ $\left(f_{\mathrm{c}}^{\prime}=63.6 \mathrm{MPa}, f_{\mathrm{ct}}=7.50 \mathrm{MPa}, E_{\mathrm{c}}=35.9 \mathrm{GPa}\right)$.

The $\mathrm{RC}$ bridge girder is assumed to be exposed to a chloride contaminated environment with a relative humidity of $75 \%$ and temperature of $20^{\circ} \mathrm{C}$. Since corrosion initiation, uniform corrosion of reinforcement is supposed to be achieved in order to use the deterministic model of Eq. 1. The corrosion current density can be predicted based on Eq. 4. The statistical parameters for the COV and distribution of input variables are same as those listed in Table 1. All the probability analysis is completed by using Monte Carlo simulation.

Figures 6 and 7 show the PDFs and 90\% confidence interval of $t_{\mathrm{cr}}$ for four durability design specifications, respectively. Clearly, low durability design specification results in a very short time to corrosion-induced cover cracking. With the improving of level of durability design specification, the time and confidence interval of $t_{\mathrm{cr}}$ increase distinctly. For $90 \%$ confidence interval of $t_{c r}$ the ranges of $[0.14,0.56]$ years, $[0.55,1.88]$ years, $[1.64,5.43]$ years, and $[3.24,10.92]$ years are obtained for low, moderate, high, and extreme durability design level, respectively. As a result, it can be concluded that the difficulty in precise prediction with deterministic model will augment for good durability design specification, which has large range of $t_{\mathrm{cr}}$.

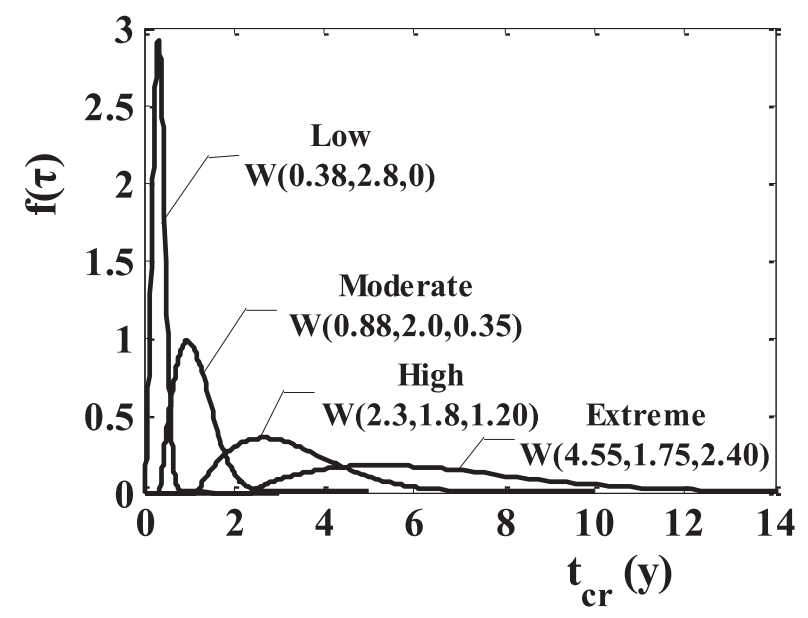

Figure 6. PDFs of $t_{\mathrm{cr}}$ for four durability design specifications.

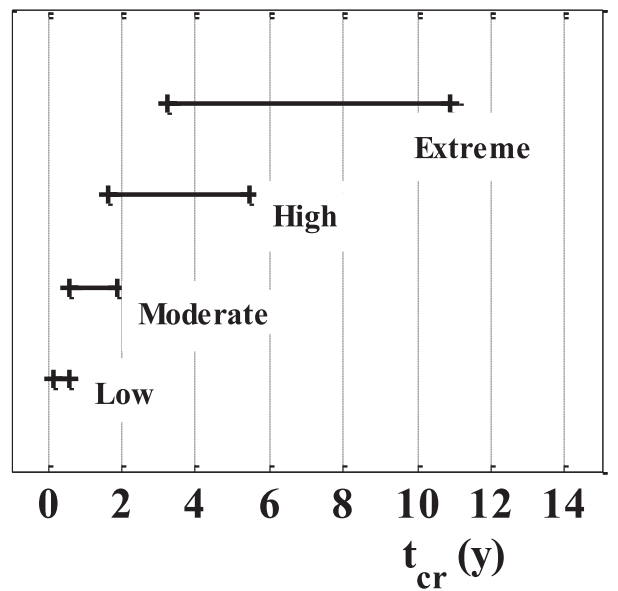

Figure 7. $90 \%$ confidence interval of $t_{\mathrm{cr}}$ for four durability design specifications. 


\section{CONCLUSION}

The following conclusions can be drawn from the present study:

Due to the random natures of the main influencing parameters, such as cover thickness, mechanical properties of concrete, corrosion rate, and composition of corrosion products, it is reasonable to use probability method to predict the corrosion-induced cracking time in concrete cover. With the statistical results of the main influencing parameters, a probabilistic model to predict the cover cracking time is built by Monte Carlo simulation. It is found that the cracking time can be modeled by the Weibull distribution.

The application of probabilistic model to realistic $\mathrm{RC}$ bridge girder shows that the mean and $90 \%$ confidence interval of corrosion cracking time will increase with the improvement of durability design level, which mainly considers the cover thickness and concrete strength.

\section{ACKNOWLEDGMENTS}

The financial supports of the National Natural Science Foundation of P.R. China via Grant Nos. 51278230 and 51378241 are greatly acknowledged.

\section{REFERENCES}

Ahmed, S. F. U., Maalej, M., \& Mihashi, H. (2007). Cover cracking of reinforced concrete beams due to corrosion of steel. ACI Materials Journal, 104(2), 153-161.

Alonso, C., Andrade, C., Rodriguez, J., \& Diez, J. M. (1998). Factors controlling cracking of concrete affected by reinforcement corrosion. Materials and Structures, 31, 435-441.

Andrade, C., Alonso, C., \& Molina, F. J. (1993). Cover cracking as a function of rebar corrosion: Part I-experimental test. Materials and Structures, 26, 453-464.

Bazant, Z. P. (1979). Physical model for steel corrosion in concrete sea structures-application. Journal of the Structural Division, 105(6), 1155-1166.

Bhargava, K., Ghosh, A. K., Mori, Y., \& Ramanujam, S. (2005). Modeling of time to corrosioninduced cover cracking in reinforced concrete structures. Cement and Concrete Research, 35(11), 2203-2218.

Chen, D., \& Mahadevan, S. (2008). Chloride-induced reinforcement corrosion and concrete cracking simulation. Cement and Concrete Composites, 30(3), 227-238.

Hansen, E. J., \& Saouma, V. E. (1999). Numerical simulation of reinforced concrete deterioration: Part II-steel corrosion and concrete cracking. ACI Material Journal, 96(3), 331-338.
Kirkpatrick, T. J., Weyers, R. E., AndersonCooka, C. M., \& Sprinkel, M. M. (2002). Probabilistic model for the chloride-induced corrosion service life of bridge decks. Cement and Concrete Research, 32(12), 1943-1960.

Li, C. Q., Melchers, R. E., \& Zheng, J. J. (2006). Analytical model for corrosion-induced crack width in reinforced concrete structures. ACI Structural Journal, 103(4), 479-487.

Liu, Y. P., \& Weyers, R. E. (1998). Modeling the time to corrosion cracking in chloride contaminated reinforced concrete structures. ACI Materials Journal, 95(6), 675-681.

Lu, C. H., Jin, W. L., \& Liu, R. G. (2011). Reinforcement corrosion-induced cover cracking and its time prediction for reinforced concrete structures. Corrosion Science, 53(4), 1337-1347.

Maaddawy, T. E., \& Soudki, K. (2007). A model for prediction of time from corrosion initiation to corrosion cracking. Cement and Concrete Composites, 29(3), 168-175.

Morinaga, S. (1988). Prediction of service lives of reinforced concrete buildings based on rate of corrosion of reinforcing steel (Report No. 23) Japan: Shimizu Corp, pp. 82-83.

Oh, B. H., \& Jang, B. S. (2003). Chloride diffusion analysis of concrete structures considering the effects of reinforcements. Farmington Hills, MI: $\mathrm{ACl}$.

Oh, B. H., Kim, K. H., \& Jang, B. S. (2009). Critical corrosion amount to cause cracking of reinforced concrete structures. ACI Materials Journal, 106(4), 333-339.

Pantazopoulou, S. J., \& Papoulia, K. D. (2001). Modelling cover-cracking due to reinforcement corrosion in RC structures. Journal of Engineering Mechanics, 127(4), 342-351.

Rasheeduzzafar, Al-Saadoun, S. S., \& Al-Gahtani, A. S. (1992). Corrosion cracking in relation to bar diameter, cover, and concrete quality. Journal Material and Civil Engineering, 4(4), 327-343.

Steward, M. G., \& Mullard, J. A. (2007). Spatial timedependent reliability analysis of corrosion damage and the timing of first repair for RC structures. Engineering Structures, 29(7), 1457-1464.

Suo, Q., \& Stewart, M. G. (2009). Corrosion cracking prediction updating of deteriorating RC structures using inspection information. Reliability Engineering and System Safety, 94(8), 1340-1348.

Thoft-Christensen, P. (2000). Stochastic modelling of the crack initiation time for reinforced concrete structures. In: Proceedings of ASCE Structures Congress, Philadelphia, PA, May 8-10, 2000, pp 1-8. 
Tikalsky, P. J., Pustka, D., \& Marek, P. (2005). Statistical variations in chloride diffusion in concrete bridges. ACl structural Journal, 102(3), 481-486.

Val, D. V., \& Trapper, P. A. (2008). Probabilistic evaluation of initiation time of chloride-induced corrosion. Reliability Engineering and System Safety, 93(3), 364-372.
Vu, K. A. T., \& Stewart, M. G. (2000). Structural reliability of concrete bridges including improved chloride-induced corrosion models. Structural Safety, 22(4), 313-333.

Vu, K. A. T., \& Stewart, M. G. (2005). Predicting the likelihood and extent of reinforced concrete corrosion-induced cracking. Journal of Structural Engineering, 131(11), 1681-1689. 